\title{
Academics speak up
}

Global Climate Change Week (GCCW) will take place for the first time on 19-25 October this year. The name doesn't give much away, so just what is GCCW and where did it all begin?

The event aims to bring together academics from across all disciplines to share ideas and engage with students and the broader community on climate change action and solutions. As Helen McGregor, a palaeoclimatologist on the coordinating committee, explains "academics who aren't climate scientists want to support their climate science colleagues ... [climate change is] an important enough issue that affects so many spheres, we want to send a message that something has to happen, we have to get people on board".

The idea behind GCCW came from Keith Horton, a moral and political philosopher at the University of Wollongong, Australia. Horton had previously co-founded Academics Stand Against Poverty (http://academicsstand.org): "the aim was to get academics more active and to have some influence in the real world on poverty". Although there are obvious links between climate change and poverty, climate change was not a focus of this group because when it was established, back in 2009, it seemed that "there was so much momentum behind climate change that we can leave it alone because we still need more focus on poverty". However, Horton's thinking shifted as progress has stalled on climate action, and the idea of GCCW - a vehicle for academics who have not had a way to engage in the climate change discussion - came about.

The concept has become a reality with the first committee meeting back in December 2014. Moving forward there was refinement of the aims and recruitment of an advisory panel,

followed by the website launch and opening of registration. The website (http://globalclimatechangeweek.com) allows people to register as a participant and add planned activities, which are complied onto a global map. "We also have what we are calling university champions, they can come on board and champion a range of events at their university, in a facilitator role" explains McGregor.

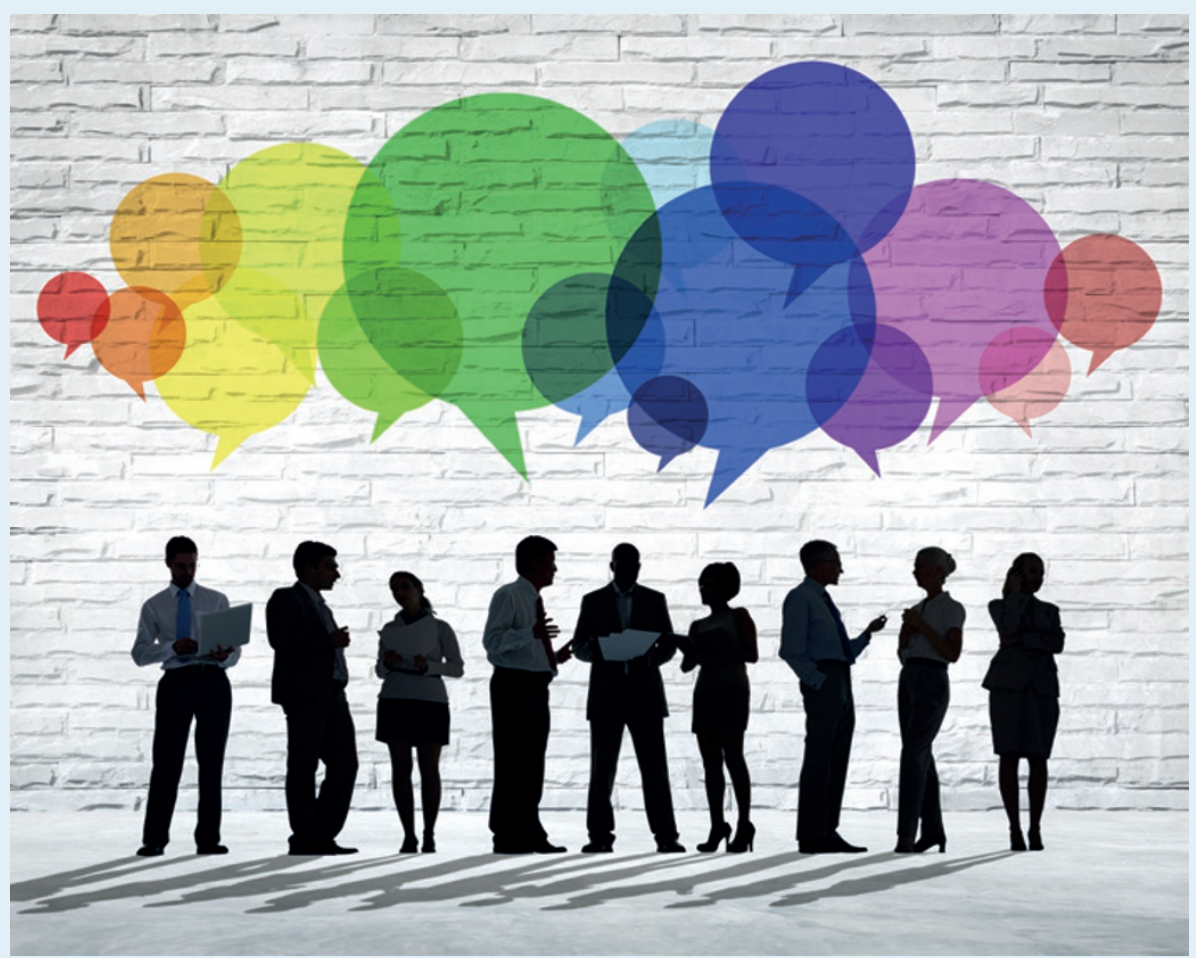

As of 21 July there were 100 registrations, coming from 24 countries across six continents. At the time of writing (with over 125 registrations) momentum is building, and the variety of people and activities is well on the way to making this first GCCW a success. "If we can lead more academics to do a bit more I think [GCCW] will be a success ... It is intended to run every year and I'm hoping that we can build on whatever we achieve this year to do more next year and forthcoming years" notes Horton.

The desire for input across disciplines seems to be working, with climate scientists in the minority of registered participants. This may be because these researchers already have a platform to share their voice, whereas other disciplines haven't had the opportunity to speak up. The coordinating committee are suggesting ideas for how people can take part, but as Horton puts it "it's about selling the basic idea, a few resources and people can put it into action in the way that they consider best in their particular circumstances." Typically people are committing to including climate change in their teachings, across subject areas from rural development to education, or making themselves available to guest lecture. An example of a slightly different activity has been registered by Lisa Roberts, an artist at University of Technology, Sydney, who intends to "show how a global movement of scientists and artist co-investigate how living things (including us) respond to climate change, and how we cocreate art and co-author publications". In India, Arundhati Vishwasrao of the University of Pune will be designing an 'Environmental Education Lab', which will introduce people to various environmental situations, in the hopes that they will choose environmentally friendly actions in the real world.

This initiative is one of many events going on this year (see http://go.nature.com/HMwbpx for other examples), but all are pushing towards a common goal and reaching different audiences. GCCW aims to be a week of activities spread around the globe, adding to the groundswell of events and voices.

BRONWYN WAKE 